\title{
Laboreal
}

Volume $12 \mathrm{~N}^{\circ} 1 \mid 2016$

Os Equipamentos de Proteção Individual (EPI):

protetores, mas nem sempre

\section{Dificuldades e limitações das luvas de proteção usadas no corte manual da cana}

Las dificultades y limitaciones de los guantes de protección utilizados en el corte manual de la caña

Difficultés et limites des gants de protection utilisés dans la coupe manuelle de la canne à sucre

Difficulties and limitations of protective gloves used in the manual cutting of sugarcane

Maria Cristina Gonzaga e Cristiane Queiroz Barbeiro Lima

URL: http://journals.openedition.org/laboreal/3268

DOI: 10.4000/laboreal.3268

ISSN: 1646-5237

\section{Editora}

Universidade do Porto

\section{Refêrencia eletrónica}

Maria Cristina Gonzaga e Cristiane Queiroz Barbeiro Lima « Dificuldades e limitacões das luvas de proteção usadas no corte manual da cana », Laboreal [Online], Volume $12 \mathrm{~N}^{0} 1$ | 2016, posto online no dia 01 julho 2016, consultado o 10 dezembro 2020. URL : http://journals.openedition.org/laboreal/ 3268 ; DOI : https://doi.org/10.4000/laboreal.3268

Este documento foi criado de forma automática no dia 10 dezembro 2020

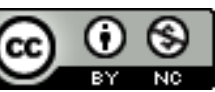

Laboreal está licenciado com uma Licença Creative Commons - Atribuição-NãoComercial 4.0 Internacional. 


\section{Dificuldades e limitações das luvas de proteção usadas no corte manual da cana}

Las dificultades y limitaciones de los guantes de protección utilizados en el corte manual de la caña

Difficultés et limites des gants de protection utilisés dans la coupe manuelle de la canne à sucre

Difficulties and limitations of protective gloves used in the manual cutting of sugarcane

Maria Cristina Gonzaga e Cristiane Queiroz Barbeiro Lima

\section{NOTA DO EDITOR}

http://dx.doi.org/10.15667/laborealxii0116mcg

Manuscrito recebido em: março/2016

Aceite após peritagem: junho/2016

\section{Introdução}

$1 \quad 0$ arsenal de Equipamentos de Proteção Individual (EPI) utilizados para proteger os trabalhadores no corte manual da cana de açúcar não tem atendido às expectativas de segurança, em especial, ao que diz respeito às luvas de proteção.

2 Muitos trabalhadores são lesionados com o uso das luvas, o que provoca dor e sofrimento, principalmente, pelo fato de que a manutenção do emprego está condicionada ao uso destes equipamentos. $\mathrm{O}$ uso compulsório dos EPI no meio rural 
esta previsto no item 31.20.1.2 da Norma Regulamentora $\mathrm{n}^{\mathrm{o}} 31$ do Ministério do Trabalho e Emprego (BRASIL, 2005).

3 O estudo de Neto, Resende e Alvares (1989) sobre facão e luvas de proteção utilizadas no corte manual da cana-de-açúcar identificou que a luva de proteção causa ferimentos, pois, durante o processo, a cana é queimada, depositando cinzas; essas cinzas, em contato com a sacarose e a água, formam uma mistura que, em contato com as luvas de raspa, penetram na pele das mãos. Este processo produz descamações, fissuras e dermatites nas mãos. 0 facão também contribui para o aparecimento de lesões nas mãos, pois geralmente o cabo de madeira não tem uma boa aderência na mão com a luva de raspa. Armstrong (1985) e Buchoholz, Frederick e Armstrong (1988) descreveram que o peso e a forma de pega da ferramenta, o tamanho, a superfície de atrito e a espessura do material com o qual são confeccionadas as luvas têm influência na força de preensão.

4 Em análise coletiva do trabalho de corte manual da cana-de-açúcar (Ferreira, Gonzaga, Donatelli \& Bussacos, 1998, p. 32), destacam-se as estratégias utilizadas pelos trabalhadores para se protegerem das luvas:

“[...] quando emborrachei o cabo do facão, amenizou um pouco o problema para o uso da luva. Cortei uma faixa de pneu de bicicleta e enrolei no cabo. Foi quando parece que segurou mais, aí [minha mão] parou de rachar [...]".

5 A comparação de algumas habilidades entre mão nua e mão com luvas demonstrou que a força de preensão com a mão nua é excelente, já com a mão enluvada é ruim, o mesmo ocorrendo com a destreza e a habilidade de manipulação (Muralidhar, Bishu \& Haldeck, 1999).

6 Em pesquisa realizada pela Fundacentro em 2004 junto ao Sindicato dos Empregados Rurais de Araraquara e a uma agroindústria do setor canavieiro do Estado de São Paulo, observou-se que todos os EPI utilizados no corte manual da cana-de-açúcar apresentavam problemas, tais como: luvas sem aderência ao cabo do facão, óculos que inviabilizam a visão, perneiras que feriam os joelhos e sapatos de segurança que machucavam os pés (Gonzaga, 2004).

7 Os problemas relacionados às ineficiências dos equipamentos de proteção são também apontados por Veiga, Duarte, Meirelles, Garrigou e Baldi (2007) que avaliaram o uso de EPI na aplicação de agrotóxicos na cultura do tomate e constataram o desconforto térmico, principalmente nos dias quentes, e o embaçamento das máscaras faciais pela respiração. Discutem a possibilidade dos EPI apresentarem lacunas funcionais no projeto, na concepção, no uso, na manutenção, no armazenamento e no descarte. Destacam a falta de análises antropométricas dos usuários na fase de concepção e a inevitável inadequação dos equipamentos, as luvas de proteção com folgas excessivas e as mangas de camisas que deixavam o punho descoberto.

8 Os trabalhadores relatam as dificuldades diárias no uso das luvas de proteção:

"No treinamento antes da safra, eles disseram que quando a luva, da mão que abraça a cana estiver sem o arame, você tem que trocar, pois se ocorrer um acidente você perde seus direitos pelo fato de não ter trocado a luva, mas, quando você vai pedir a troca, mandam esperar mais um tempo. Quem ganha com isso?" (Faccioli, 2009, p.20). 
No Brasil, a condição para que um EPI seja comercializado legalmente é a obtenção do Certificado de Aprovação (CA), emitido pelo Ministério do Trabalho e Emprego. Mas perante a realidade encontrada, o que significa este certificado e até que medida assegura a proteção do trabalhador em situação real de trabalho?

O presente estudo discute as dificuldades e limitações das luvas de proteção no corte manual da cana e analisa o processo da obtenção dos certificados de aprovação, desenvolvendo a problemática do distanciamento entre normas de ensaios para fabricação de equipamentos de proteção e as reais necessidades dos usuários perante a atividade exercida.

\title{
2. O trabalho no corte manual da cana
}

11 O espaço de trabalho dos cortadores de cana é o canavial com as seguintes características:

\begin{abstract}
"Um canavial é dividido em talhões e cada talhão é composto por linhas de cana plantadas em paralelo, o espaçamento entre as linhas formam as ruas, que variam de acordo com a topografia do terreno, o tipo de solo, a variedade de canas, o tipo de corte - manual ou mecanizado. As linhas de cana agrupadas formam o eito, no Estado de São Paulo o eito é formado por 5 ruas de cana, esse é o espaço de trabalho de cada trabalhador, ou seja, o trabalhador tem 1 eito a ser cortado num dia de trabalho. $O$ corte manual da cana é uma atividade executada ao ar livre, portanto está sujeita ao calor intenso, a chuva, aos raios, aos animais peçonhentos" (Ferreira et al., 1998, p. 13).
\end{abstract}

12 Esse trabalho é composto basicamente de quatro tarefas. Munido de um facão afiado em uma das mãos, o cortador deve: (1) cortar a cana; (2) despontar a cana; (3) limpar o eito da cana já cortada; (4) organizar a cana cortada na terceira rua do eito.

13 A mão que não segura o facão abraça cana de forma permitir cortar um feixe. A mão que segura o facão executa o corte, em movimentos contínuos de acordo a posição da cana a ser cortada: em pé ou caída.

14 De acordo com Gonzaga (2002), estas tarefas são previamente definidas pela empresa, que faz exigências para atender ao Sistema de Gestão de Qualidade Total - ISO 9002, por exemplo:

- corte deve ser rente ao solo;

- desponte deve ser feito no último gomo da cana;

- A leira (cana cortada organizada em linha reta) deve ser feita na terceira rua do eito e ficar limpa em todo o seu comprimento, com no mínimo $50 \mathrm{~cm}$ de cada lado livre de palhas.

Essas exigências estão relacionadas ao fato de que o trabalho dos cortadores (as) de cana tem como finalidade suprir as necessidades da agroindústria do álcool e do açúcar. Isto transfere as exigências industriais aos sistemas de produção agrícola, por exemplo: o corte rente ao solo se deve ao fato de que a sacarose fica concentrada no pé da cana; o desponte deve ser no último gomo para eliminar impurezas vegetais; a leira deve ficar na terceira rua do eito e limpa no mínimo $50 \mathrm{~cm}$ de cada lado para facilitar o carregamento feito por máquinas agrícolas. A organização da cana em leiras também é imposta para viabilizar o movimento de máquinas que irão carregar a cana até a indústria. 
16 A cana a ser cortada pode estar crua ou queimada, pode estar em pé, tombada, caída, enraizada Sabe-se que, na cana crua ou com folhas, as dificuldades são imensas, pois ela tem que ser limpa de toda massa de folhas cortantes que é coberta por joça (pequenos pelos da folha da cana) extremamente irritante, além da presença de animais peçonhentos, como cobras, aranhas, escorpiões, já que é a queimada da cana que os elimina.

17 Já na cana queimada, o corte é mais fácil, entretanto, Bosso (2004) constatou, em estudo realizado nas safras 2002 e 2003 junto a 39 cortadores de cana queimada, não fumantes, na região de Catanduva, que o nível de Hidrocarbonetos policíclicos aromáticos (HPAs) na urina dos cortadores de cana foi noves vezes maior que na entressafra. Destacou ainda que a exposição a esses agentes químicos representa um risco maior para o desenvolvimento de doenças degenerativas, como enfermidades cardiorrespiratórias e câncer.

Os fatores descritos interferem na produtividade dos trabalhadores (as), o que consequentemente tem reflexos no seu salário, que é pago por produção com base na tonelada de cana cortada.

19 Os cortadores devem executar seu trabalho usando luvas de proteção nas duas mãos, óculos de proteção, sapato de segurança, perneira e mangote.

\section{0 uso de luvas na atividade de corte manual da} cana

20 As situações descritas nesse trabalho foram identificadas e analisadas a partir de pesquisa realizada durante o ano de 2009, sobre a utilização de luvas de proteção na atividade do corte manual da cana, em 5 usinas de açúcar no Estado de São Paulo e uma usina no Estado de Goiás. Envolveu 165 trabalhadores, sendo entrevistados em média trinta trabalhadores por empresa, durante um dia de trabalho. Foram utilizados questionários e entrevistas semiestruturadas, estando o foco na compreensão e não na mensuração da problemática.

21 Foi desenvolvido um levantamento bibliográfico a respeito das normas de fabricação e certificação de EPI e estudos realizados com cortadores de cana que abordam os problemas do uso de EPI nos canaviais.

22 As pesquisas demonstraram a necessidade de luvas diferentes para as mãos direita e esquerda. Já que para a mão que segura o cabo do facão, o importante é que o material da luva seja bastante aderente ao cabo do facão, e a outra mão deve estar protegida com luva de material resistente ao golpe do facão no momento do corte da cana.. (Ferreira et al., 1998; Gonzaga, 2002; Gonzaga, 2004).

\section{Equipamento de Proteção Individual: fabricação e normas}

23 Considera-se EPI todo dispositivo ou produto, de uso individual, utilizado pelo trabalhador, destinado à proteção de riscos suscetíveis de ameaçar a segurança e a saúde no trabalho. De acordo com a CLT- Consolidação das Leis do Trabalho , art. 166, 
toda empresa é obrigada a fornecer aos empregados, gratuitamente EPI adequado ao risco e em perfeito estado de conservação e funcionamento (BRASIL, 1977).

No Brasil, o EPI de fabricação nacional ou importado só pode ser posto à venda ou utilizado legalmente após a obtenção do Certificado de Aprovação (CA), expedido pelo Departamento de Segurança e Saúde no Trabalho - DSST/Ministério do Trabalho e Emprego - MTE. O DSST cadastra o fabricante ou importador de EPI, examina a documentação exigida para emitir ou renovar o $\mathrm{CA}$, estabelece os regulamentos técnicos para ensaios de EPI, bem como é responsável por fiscalizar a qualidade do EPI e ou suspender o cadastramento da empresa fabricante ou importadora e ainda cancelar o CA.

A Portaria no 25 do MTE (BRASIL, 2001), da Secretaria de Inspeção do Trabalho do MTE, introduziu a participação do Sistema Brasileiro de Normalização, Metrologia e Qualidade Industrial - SINMETRO no processo de avaliação da conformidade dos EPI, conforme previsto no item 6.8.1, alínea j, da Norma Regulamentadora 6. Contudo, o acordo de Cooperação Técnica entre o INMETRO e o MTE, foi publicado 6 anos depois, em 21 de setembro de 2007.

\subsection{Fabricação}

Um fabricante nacional ou um importador que deseje comercializar determinado EPI, deve cadastrar-se junto ao DSST, solicitar a emissão do CA, sua renovação ou requerer novo CA.

De acordo com a Portaria $n^{\circ} 121^{[1]}$ do MTE (BRASIL, 2009), os EPI destinados à proteção das mãos devem possuir na sua embalagem as seguintes informações: tamanhos disponíveis; medidas da circunferência e comprimento das mãos; instruções de uso, conservação e limpeza; efeitos secundários de danos à saúde, provocados ou causados pelo uso das luvas, como alergias, dermatoses, entre outros; efeitos secundários de ampliação do risco de acidentes decorrentes do uso de luvas, especialmente na operação de máquinas, equipamentos ou atividades com contato com partes móveis; efeitos secundários de perda ou redução da sensibilidade táctil e da capacidade de preensão; indicação, caso a proteção esteja limitada a apenas uma parte da mão; especificação, caso o uso seja recomendado para apenas uma das mãos ou ainda se haja indicação para o uso de luvas diferentes em cada mão.

28 A Portaria n. 126 (BRASIL, 2009a), que estabelece procedimentos para o cadastro de empresas e para a emissão ou renovação do CA de EPI, exige que o fabricante ou importador apresente vários documentos, entre eles: o memorial descritivo do EPI (descrição das características e especificações técnicas do EPI; descrição dos materiais empregados; descrição do uso a que se destina o EPI e suas correspondentes restrições; descrição das possíveis variações do EPI, tais como: referência, tamanho, numeração).

Cabe ressaltar os princípios obrigatórios a serem seguidos na concepção e fabricação de EPI, propostos pela Portaria 121 (BRASIL, 2009), tais como: concepção e fabricação que propicie dentro das condições normais das atividades o nível mais alto possível de proteção, conforto e a facilidade de uso por diferentes grupos de trabalhadores, em diferentes tipos de atividades e de condições ambientais; concepção de EPI de forma a não acarretar riscos adicionais ao usuário e não reduzir ou eliminar sentidos importantes para reconhecer e avaliar os riscos das atividades; todas as partes do EPI em contato com o usuário devem ser desprovidas de asperezas, saliências ou outras 
características capazes de provocar irritação ou ferimentos; EPI devem adaptar-se à variabilidade de morfologias do usuário; permitir uma completa liberdade de movimentos, sem comprometimento de gestos, posturas ou destreza; devem ser tão leves quanto possível, sem prejuízo de sua eficiência; os materiais utilizados na fabricação não devem apresentar efeitos nocivos à saúde. A concepção e fabricação dos EPI que se destinam a proteger simultaneamente contra vários riscos devem satisfazer as exigências específicas de cada um desses riscos e de possíveis sinergias entre eles.

\subsection{Normas de ensaio para aprovação de EPI - Luvas de proteção} no corte manual da cana, os ensaios são voltados para os agentes abrasivos e escoriantes, cortantes e perfurantes previstos nas normas européias EN 420: 2003 General requirements for gloves e Norma EN 388:2003 - Protective gloves against mechanical: e na ISO 13999: 1999 - Protective Clothing - Gloves and arm guards protecting against cuts and stabs by hand knives - Part 1 e 2: 2003 - Norma para luvas de proteção em malhas de aço e outros materiais alternativos. abrasão, resistência ao corte por lâmina; resistência ao rasgo; resistência a perfuração por punção. A norma prevê uma classificação de proteção para as luvas contra riscos mecânicos por meio de níveis de desempenho que variam de 0 (zero) a 4 (quatro) para abrasão, para rasgamento, para perfuração; e de 0 (zero) a 5 (cinco) para corte por lâmina sem impacto. Quanto maior a classificação, maior o nível de desempenho, maior a proteção. Ressalta-se que não existe o ensaio para corte por impacto.

A norma ISO 13999 é elaborada pelo Comitê Técnico ISO de equipamentos e roupas de proteção e consiste de duas partes. A parte 1, norma ISO 13999 publicada em 1999, especifica requisitos para a confecção, resistência a penetração, características ergonômicas, peso, material, identificação e rotulagem, instruções para o uso, bem como especifica os métodos de ensaios apropriados. A parte 2, norma ISO 13999 publicada em 2003, se aplica às luvas que não são fabricadas em malha de aço e que apresentam proteção limitada das mãos ao corte. Essa norma propõe requisitos de confecção e métodos de ensaios incluindo testes ergonômicos utilizando-se de pessoas com tamanhos de mãos e braços apropriados às luvas, que testam as luvas com relação a conforto e tamanho.

\subsection{Luvas analisadas}

A empresa A fornecia dois tipos de luvas para o corte da cana, a Luva Crilicana Antiderrapante, para a mão do facão com CA 15109, e a Luva Crilicana com Cabo, para mão da cana com CA 10441. A empresa B e a empresa C forneciam Luvas Grafatex com 
CA 20368. A empresa D fornecia Luva Dublatex 01 com CA 14205. A empresa E, fornecia a luva de proteção com CA 17452. A empresa F fornecia opção de dois modelos de luvas de proteção para a mão do facão: uma luva de CA 16906 e outra de CA 20854, ficando a critério do trabalhador qual usar. Para a mão da cana eram utilizadas até três luvas em conjunto, ou seja, ao mesmo tempo. Uma luva de CA 10572, tricotada em fio de helanca, embaixo de uma luva de CA 6536, tricotada em fios de aço que é usada sob outra luva de CA 16906 ou de CA 20.854 conforme escolha do trabalhador.

\subsection{As luvas de proteção e seus respectivos níveis de desempenho}

A tabela 1 apresenta a classificação de proteção correspondente a cada risco mecânico previsto, em cada luva identificada pelo seu respectivo CA. Observa-se que para um CA, pode haver níveis de proteção diferentes, para luvas de mãos diferentes, como é o caso das luvas de CA 20368, que tem níveis de desempenho 4142 para a mão do facão e 4243 para a mão da cana, assim como, o CA 20854 que tem níveis de desempenho 4342 para a mão do facão e 4441 para a mão da cana.

Tabela 1. Luvas de proteção e seus respectivos níveis de proteção

\begin{tabular}{|l|l|l|}
\hline $\begin{array}{l}\text { Certificado de Aprovação } \\
\text { (CA) }\end{array}$ & Mão da luva & Proteção - Níveis de desempenho \\
\hline 15109 & Mão do facão & 3242 \\
\hline 10441 & Mão da cana & 4442 \\
\hline 20368 & Mão do facão & 4142 \\
\hline 20368 & Mão da cana & 4243 \\
\hline 14205 & $\begin{array}{l}\text { Mão do facão e da } \\
\text { cana }\end{array}$ & 3442 \\
\hline 17452 & $\begin{array}{l}\text { Mão do facão e da } \\
\text { cana }\end{array}$ & 4242 \\
\hline 20854 & Mão do facão & 4342 \\
\hline 20854 & Mão da cana & $\mathbf{4 4 4 1}$ \\
\hline 16906 & Mão do facão & $\begin{array}{l}\text { Sem classificação quanto ao da canel de } \\
\text { desempenho }\end{array}$ \\
\hline 6536 & Mão da cana & $3 X 41$ e 3X42 \\
\hline 10572 & 0041 \\
\hline
\end{tabular}

Os níveis de desempenho de proteção estabelecidos para cada luva são os correspondentes aos CA, registrados no Ministério do Trabalho. 

tem desempenho de proteção considerado alto (4) para abrasão e rasgamento e baixo (2) para corte por lâmina sem impacto e perfuração. Uma trabalhadora contou ter sofrido um acidente com essa luva: "quando amolava o facão a cobra furou a luva desta mão".

níveis de proteção da luva com CA 10441, quando usada na mão da cana, são de 4442. Essa luva tem alto desempenho (4) para abrasão, corte por lâmina sem impacto e rasgamento e baixo (2) para perfuração. Os relatos feitos por alguns cortadores de cana sobre os acidentes ocorridos com essa luva foram: "o facão pegou o dedão, tive que levar pontos; no corte da cana para mudas, sofri um acidente, onde cortei o dedo indicador e o polegar; os cabos de aço estavam soltos, cortei os cabos de aço da luva e sofri um acidente, no dedo indicador".

Os níveis de proteção da luva com CA 20368, quando na mão da cana, são de 4243.Indica que a luva tem alto desempenho (4) para abrasão e rasgamento, médio desempenho (3) para perfuração e baixo (2) para corte por lâmina sem impacto. Os trabalhadores relataram os seguintes acidentes ao utilizarem esta luva: "cortei o dedo indicador, pois a luva grafatex não protege do golpe do facão; sofri um acidente, pois a luva não era resistente ao corte; nas luvas velhas os fios saem e machucam as mãos, pois a luva apodrece, a troca tem que ser feita antes que a luva comece apodrecer, assim evita a saída dos fios internos das luvas".

41 Os níveis de proteção do CA 14205 para as luvas usadas na mão da cana e do facão são 3442. Indica que a luva tem alto desempenho (4) para corte sem impacto e rasgamento, médio desempenho (3) para abrasão e baixo (2) para perfuração. Os relatos obtidos se referiram a acidentes ocorridos na mão da cana: "o facão pegou as costas da mão; o facão cortou as pontas dos dedos; com 10 dias os fios de aço se soltam da luva e a minha mão fica inflamada; os fios de aço se soltam com facilidade, mesmo na luva nova, por isto, sofri um acidente onde cortei as pontas de 4 dedos".

42 Os níveis de proteção do CA 17452 para as luvas usadas na mão da cana e do facão são 4242. Indica ter alto desempenho (4) para abrasão e rasgamento, e baixo desempenho (2) para perfuração e corte por lâmina sem impacto. Para essa luva há relatos de acidentes nas duas mãos: "o facão amolado pegou no capim colonião, escorregou e me feriu; a mão do facão fica cheia de ferimentos e bolhas; retiro os fios de aço da luva, da mão da cana, pois eles me machucam; cortei o dedo indicador com o facão; cortei a parte superior da mão".

43 A luva com o CA 16906, por ser confeccionada em raspa de couro, passou por ensaios segundo a NBR 13712 - Luvas de proteção, não mais utilizada. Esta norma não propõe informações sobre nível de proteção por desempenho e não faz diferenciação entre uma mão e outra.

Os níveis de proteção das luvas de CA 20854 são 4342 e 4441, luvas da mão do facão e da mão da cana, respectivamente. 0 nível de proteção da luva da mão do facão indica ter alto desempenho (4), para abrasão e rasgamento, médio desempenho (3) para corte por lâmina sem impacto e baixo (2) para perfuração. Para essa luva houve uma descrição de acidente: o facão escorregou e me feriu nas costas das mãos. A classificação de desempenho da luva da mão da cana indica ter alto desempenho (4) para abrasão, rasgamento e corte sem impacto e baixíssimo desempenho (1) para perfuração. Os depoimentos sobre acidentes ocorridos com essa luva foram: "o facão atingiu o dedão e 
o meio da mão, cortou a luva de couro, mas a luva de aço segurou e não feriu a mão; o facão cortou as costas da mão com as 2 luvas (couro mais aço ), levei pontos".

A classificação de proteção da luva de CA 6536, luva em malha de aço, é 3X41 e 3X42. De acordo com a Norma BS EN 420:2003 o símbolo "X" indica que a luva não foi submetida ao teste de corte por lâmina sem impacto. A luva de CA 6536 tem médio desempenho (3) para abrasão, não fornece informações $(\mathrm{X})$ para a resistência ao corte por lamina sem impacto, tem alto desempenho (4) para rasgamento e apresenta baixo e baixíssimo desempenho (2 e 1) para perfuração.

A classificação de desempenho da luva com o CA 10572, para a mão da cana é 0041. Indica desempenho nulo (0) para abrasão e corte por lâmina sem impacto, alto desempenho (4) para rasgamento, e baixíssimo desempenho (1) para perfuração.

o nível de desempenho apresentado, em especial os da mão da cana, não tem correspondido à proteção necessária aos fatores de riscos presentes no corte manual da cana, pois o principal fator de risco - o corte por impacto pelo facão não é contemplado nas classificações apresentadas.

\subsection{Avaliação qualitativa das luvas de proteção utilizadas no corte manual da cana de açúcar}

\subsubsection{Luvas utilizadas na mão do facão}

$\mathrm{Na}$ Empresa A, foram entrevistados 30 trabalhadores (as) (12 homens e 18 mulheres). Entretanto, apenas 24 (8 homens e 16 mulheres) usavam na mão do facão a luva com o CA 1510; 1 homem e 1 mulher não usavam luvas; 3 homens e 1 mulher usavam outras luvas por eles trazidas.

Nas empresas B e C, foram entrevistados 43 homens, dos quais 31 usavam a luva de CA 20368 na mão do facão, 5 não usavam luva nesta mão, 7 usavam outras luvas por eles trazidas.

Na empresa D, foram entrevistados 29 trabalhadores (as) (18 homens e 11 mulheres). Todavia a análise da luva de CA 14205 usada na mão que segura o facão foi de 27 trabalhadores (11 mulheres e 16 homens), 2 mulheres não utilizavam luva nesta mão.

$\mathrm{Na}$ empresa $\mathrm{E}$, foram entrevistados 30 homens, dos quais 24 usavam a luva fornecida de CA 17452 na mão que manuseia o facão, 4 optaram por utilizarem outras luvas, 2 trabalhadores não usavam a luva.

Na empresa F, participaram das entrevistas 22 trabalhadores (19 homens e 3 mulheres), dos quais 20 usavam a luva de CA 16906 (2 mulheres e 18 homens), 2 trabalhadores usavam a luva em grafatex de CA 20854.

53 Os principais problemas relatados no uso das luvas na mão do facão foram:

54 a) Tamanho inadequado

O tamanho de luvas foi o principal motivo de queixas dos trabalhadores. Foram também encontrados problemas referentes a largura e comprimento dos dedos e do punho:

"Se o punho da luva fosse mais justo, ela não sairia da mão, por isto eu costuro o punho, a luva aperta os dedos nas pontas e o meio dos dedos é largo, o punho poderia ser mais comprido para proteger o braço do sol" ( luva de CA 20368). 
"As unhas e a parte superior da mão ficam todas lesionadas, pois a luva aperta; se os dedos fossem mais curtos e mais justos seria melhor; machuca minha mão, já que escorrega, por ser grande demais para mim" (luva de CA 17452).

b) Falta de aderência ao cabo do facão

Embora algumas luvas indicadas à mão do facão tenham na palma da mão pigmento antiderrapante em PVC - policloreto de vinila, para auxiliar na aderência do cabo do facão a luva, a dificuldade persiste:

"Essa luva causa formigamento nos dedos e cãibra, pois não é aderente ao cabo do facão, o que não permite segurar o facão com firmeza, por isto não uso luva na mão do facão" ( luva de CA 15109).

"O uso da luva na mão do facão contribui para que a mão fique mais cansada e os dedos adormecidos, dificultando a movimentação dos dedos e a pega do facão com firmeza; luva descama as mãos, quando o facão está molhado: pois nesta condição temos que apertar com força a luva para segurar o facão" (luva de CA 20368).

2 "Com a mão lisa, a luva escorrega no cabo do podão, isto exige muito mais força para segurar o mesmo, o que provoca muita dor nos braços e bolhas no local que segura o facão; a mão molhada incomoda muito, pois, o facão desliza na mão lisa" (luva de CA 17452).

c) Localização das costuras na empunhadura do facão

As costuras internas da luva, na empunhadura do facão (local de aplicação de força para segurar o cabo do facão) incomodam e provocam lesões nas mãos.

"Nas luvas novas as costuras machucam as mãos nos vãos dos dedos, por isto muitas vezes uso outra luva de pano" (luva de CA 14205).

"A luva machuca no dorso da mão, pois as costuras são muito grossas; como a luva é muito larga as costuras dobram, machucam a mão e destroem as unhas" (luva de CA17452).

“As costuras machucam na parte superior do dedo indicador" (luva de CA16906).

\subsubsection{Luvas utilizadas na mão da cana}

$68 \mathrm{Na}$ Empresa A, foram entrevistados 30 dos trabalhadores ( 12 homens e 18 mulheres), contudo apenas 22 (13 mulheres e 9 homens) usavam a luva com o CA 10441 na mão da cana, 1 homem e 1 mulher não usavam luva e 3 homens e 3 mulheres usavam outra luva de proteção trazidas por elas.

$69 \mathrm{Na}$ Empresa B e C, foram entrevistados 43 trabalhadores, dos quais 33 usavam a luva com o CA 203688, 8 usavam outras luvas trazidas por eles nesta mão e 2 não usavam luvas.

70 Na Empresa D, participaram das entrevistas 29 trabalhadores (18 homens e 11 mulheres), sendo que 27 usavam a luva, pois1 trabalhadora e 1 trabalhador não usavam luva nesta mão.

71 Na Empresa E, foram entrevistados 30 trabalhadores, sendo que 28 usavam a luva e 2 trabalhadores usavam outras luvas trazidas por eles.

Na Empresa F, participaram das entrevistas 22 trabalhadores (3 mulheres, 19 homens), dos quais 18 usavam a luva com o CA 16906 (2 mulheres e 16 homens) e 4 trabalhadores (1 mulher e 3 homens) usavam a luva em grafatex com o CA 20854. 

no punho para não escapar da mão; esta luva é ruim, pois é muito grande e dificulta o trabalho, luva da cana é larga e tem os dedos compridos, por isto os dedos doem, incham e adormecem, fica muito difícil trabalhar, já que é impossível segurar a cana com firmeza" (luva de CA 20368).

"Atrapalha o movimento, por ser muito comprido para o meu braço; ela fica escorregadia e amontoa no punho, pois é muito larga, o que incomoda muito" (luva de CA 10441).

b) Os materiais com que as luvas são confeccionadas

As espessuras dos materiais com os quais as luvas são confeccionadas têm limitado a flexibilidade de movimentos dos dedos e mão dos usuários:

"A luva da mão da cana impede fechar os dedos, pois ela é muito grossa, isto prejudica o trabalho e me dá muita dor nos nervos da mão; os dedos adormecem, por isto os movimentos da mão que segura a cana, ficam prejudicados; não uso na mão da cana, pois a luva não permite fechar os dedos para segurar a cana" (luva de CA 10441).

81 "A luva provoca calos nas mãos, cãibra além de muita dor. Prejudica o movimento da mão, nas horas mais quentes do dia, pois o couro endurece demais provocando calos na palma da mão, além da pele da mão se soltar" (luva de CA 16906).

c) A proteção por fios de aço

o problema mais grave das luvas com acabamento em fios de aço é que os mesmos se soltam com pouco tempo de uso e lesionam as mãos:

"Os fios de aço começam a se soltar com mais ou menos 10 dias, aí começam a machucar as mãos, pois a troca da luva é mensal" (luva de CA 20368).

"Cortei o dedo indicador, por que essa luva não protege do golpe do facão; os fios internos de aço enroscam e ferem os dedos, por isto eu retiro os fios de aço" (luva de CA 20368).

86

"A mão fica inflamada, o que prejudica os movimentos, machucam a mão, pois saem os cabos de aço, sinto cãibra com essa luva, a mão fica ferida pelos ferrinhos que se soltam" (luva de CA 14205). 
Figura 1. Fio de aço solto na luva com CA 14205

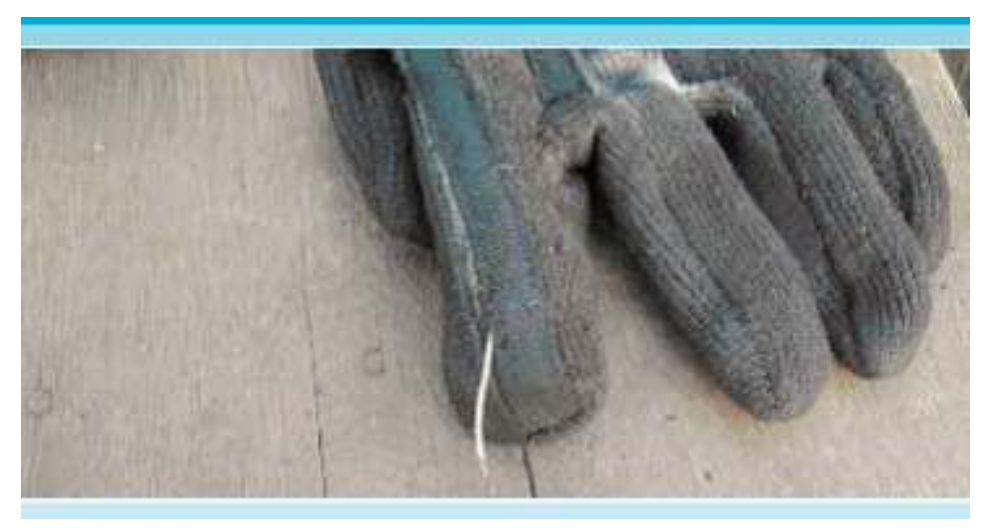

\subsubsection{Uso de 3 luvas em conjunto na mão da cana.}

87 A empresa $\mathrm{F}$ fornece para a mão que segura a cana cortada 3 luvas de proteção: a de malha aço de CA 6536, a de couro de CA 16906 ou grafatex de CA 20854 e helanca de CA 10572.

O uso conjunto é feito da seguinte forma: sobre a luva de malha de aço deve ser usada a luva em couro ou de grafatex, a luva em helanca fica em contato direto com a pele da mão e a malha de aço. Sendo o objetivo da luva de helanca o de proteger a pele da mão da luva da malha de aço. As dificuldades encontradas no uso do conjunto completo das luvas (malha aço, couro e helanca) foram:

"Quando uso o conjunto das luvas fico com a mão molhada, pois esquenta muito, adormece a mão dos dedos até o pulso, e formiga durante a noite; o conjunto das 3 luvas prejudica muito o movimento; uso só 2 luvas, a de aço e a de couro, porque depois que usei a luva de aço comecei a sentir dormência do cotovelo até a ponta dos dedos durante a noite; o conjunto malha de aço e couro: machuca as pontas dos dedos e a mão adormece. À noite a mão lateja de dor, o braço fica inchado e dói demais; pois com o conjunto tem que fazer mais força para pegar a cana; não uso o conjunto (malha de aço mais grafatex), pois esquenta e encharca mão de suor, é dura demais e não permite fechar a mão, por isto atrapalha pegar a cana; uso a luva de tricô (helanca) por baixo da luva de aço, pois a luva de aço machuca as mãos."

O local no qual as luvas de couro rasgam é na ponta dos dedos que seguram a cana: os dedos que seguram a cana rasgam ao raspar no chão; as pontas dos dedos rasgam e racham quando raspam no chão.

91 As dificuldades no uso conjunto das 3 luvas são: limitação no fechamento dos dedos das mãos, aplicação de esforço maior, sendo fatores contribuintes para as queixas de dormência, lesões e dores nas mãos, braços e ombros.

\section{Considerações finais}

O sistema de proteção por meio do uso de Equipamento de Proteção Individual vigente no Brasil apresenta-se da seguinte maneira: o trabalhador é obrigado a usar o que lhe é oferecido, pois, por razões óbvias de posição hierárquica, na realidade dificilmente contestará. Por outro lado a empresa é obrigada a fornecer o EPI adequado aos riscos 
presentes nas atividades de trabalho, procura estes no mercado e, de modo geral, compra o que está disponível.

93 É o fabricante ou importador quem desenvolve e especifica a que ou quais riscos o produto se destina. Os laboratórios credenciados sejam diretamente pelo MTE ou pelo SINMETRO, por meio de ensaios determinam níveis de desempenho ou proteção para determinados riscos, de acordo com a solicitação feita pelos fabricantes, sem entrar no mérito da adequação do mesmo à atividade. Na aplicação dos ensaios não há reprovação e sim classificação de níveis de desempenho, pelo menos para o caso dos ensaios para luvas de proteção contra riscos mecânicos.

Contudo, o Ministério do Trabalho e Emprego - DSST quando concede o CA assume toda a responsabilidade pela qualidade do mesmo. 0 produto então vai para o mercado com suas limitações de proteção e dificuldades de uso oriundos do processo de concepção sem mecanismos para garantir a conformidade pretendida já no momento da emissão do CA.

Embora os estudos semelhantes a esse, realizados em 2003/2004, demonstrassem que houve uma melhora nas condições de uso das luvas de proteção no corte manual da cana, a situação encontrada na oportunidade dessa pesquisa ainda era precária, tais como:

96 1. O fornecimento de luvas de proteção de tamanhos incompatíveis com as mãos dos usuários, prejudicando o trabalho e causando danos a saúde;

97 2. A utilização de luvas na mão da cana não resistentes ao corte por impacto do facão, portanto não protegendo contra os acidentes por corte;

98 3. Uso conjunto de duas a três luvas para proteção de riscos dificultando a destreza e proporcionando peso extra nas mãos;

4. Luvas que com pouco tempo de uso soltam espontaneamente os fios de aço, que não se sabe o quanto pode proteger, pois não passaram por nenhum ensaio que comprovasse proteção; cutucam as mãos e os dedos dos usuários, chegando em alguns casos a lesionar quando não são removidos a tempo;

5. Luvas da mão do facão com pouco tempo de uso que soltam as borrachas que deveriam garantir a aderência ao cabo do facão;

6. A não reposição imediata de luvas assim que começam a desgastar;

7. A não previsão de normas de ensaios que contemplem todos os riscos presentes na atividade de corte manual da cana e tampouco são exigidos para concessão de CA.

9. Não exigência explícita sobre a obrigatoriedade da adoção de todos os ensaios previstos nas normas para a obtenção do CA.

104 10. O processo de certificação de EPI do MTE não requisita testes em campo que contemplem as situações reais de trabalho, considerando todos os fatores de riscos presentes, ignorando os potenciais efeitos sinérgicos. Portanto, não basta que as luvas protejam as mãos contra agentes abrasivos e escoriantes, agentes cortantes e perfurantes. Há necessidade também de considerar determinadas peculiaridades tais como, flexibilidade de movimentos dos dedos e mão; facilidade de transpiração da mão; e alta aderência na mão do facão.

105 Contudo, esses estudos motivaram o Ministério do Trabalho a publicar através da Portaria no 392 um Regulamento Técnico para luvas de segurança utilizadas na atividade de corte manual de cana-de-açúcar (BRASIL, 2013). 

é quem deverá designar o tamanho da luva e considerar os materiais utilizados para a fabricação. Não existem dimensões pré-determinadas das luvas em função do tamanho, somente o comprimento total mínimo é estabelecido, entretanto, pode-se ter previsão para 6 tamanhos diferentes.

112 Espera-se que o cumprimento desse regulamento venha a colaborar para melhoria das condições encontradas.

Notas

[1] Portaria no 452 de 20 de novembro de 2014 (BRASIL, 2014) estabelece as normas para fabricação das luvas de proteção contra riscos mecânicos substituindo a Portaria 121.

\section{COMO REFERENCIAR ESTE ARTIGO?}

Gonzaga, M.C., \& Lima, C. (2016). Dificuldades e limitações das luvas de proteção usadas no corte manual da cana. Laboreal, 12 (1), XX-XX. http://XXXXXXX 


\section{BIBLIOGRAFIA}

ABNT-Associação Brasileira de Normas Técnicas (1996). NBR 13712: luvas de proteção. Rio de Janeiro.

Armstrong, T. J. (1985). Mechanical considerations of skin in work. American journal of industrial medicine, 8 (4-5), 463-472.

Bosso, R. M. V. (2004). Investigação de biomarcadores de suscetibilidade e de exposição ambiental em indivíduos ocupacionalmente expostos à queima de canaviais. Tese Doutorado em Genética, Instituto de Biociências, Letras e Ciências Exatas, Universidade Estadual Paulista (UNESP), São José do Rio Preto.

BRASIL (1977). Lei no 6.514, de 22 de dezembro de 1977. Aprova a Consolidação das Leis do Trabalho CLT. Presidência da Republica/Casa Civil. Retirado maio, 18, 2010 de http://www.planalto.gov.br/ ccivil_03/LEIS/L6514.htm\#art166.

BRASIL (2001). Portaria no 25 de 29 de dezembro de 1994. Ministério do Trabalho e Emprego. Riscos Ambientais. Retirado maio, 18, 2010 de http://www.mte.gov.br/legislacao/portarias/2001/ p_20011015_25.pdf.

BRASIL (2005). Norma regulamentadora NR 31 - segurança e saúde no trabalho na agricultura, pecuária silvicultura, exploração florestal e aqüicultura. Ministério do Trabalho e Emprego. Retirado fevereiro, 10, 2010 de http://www.mte.gov.br/legislacao/normas_regulamentadoras/ nr_31.pdf.

BRASIL (2009). Portaria nº. 121 do Ministério do Trabalho e Emprego de 30 de setembro de 2009. Estabelece as normas técnicas de ensaios e os requisitos obrigatórios aplicáveis aos Equipamentos de Proteção Individual. Retirado maio, 10, 2010 de http://www.mte.gov.br/legislacao/portarias/2009/ p_20090930_121.pdf.

BRASIL (2009a). Portaria n. 126 do Ministério do Trabalho e Emprego de 02 de dezembro de 2009. Estabelece procedimentos para o cadastro de empresas e para a emissão ou renovação do Certificado de Aprovação de Equipamento de Proteção Individual. Retirado maio, 23, 2010 de .http:// www.mte.gov.br/legislacao/portarias/2009/p_20091202_126.pdf.

BRASIL (2013). Portaria no 392, de 18 de julho de 2013. Aprova o Regulamento Técnico para luvas de segurança utilizadas na atividade de corte manual de cana-de-açúcar. O Regulamento Técnico para luvas de segurança utilizadas na atividade de corte manual de cana-de-açúcar. Retirado fevereiro, 3, 2014 de http://acesso.mte.gov.br/data/files/FF808081475961470147642EC1806B15/ Portaria\%20n.\%C2\%BA\%20392\%20(RAC\%20Luvas\%20Corte\%20de\%20Cana-deA\%C3\%A7\%C3\%BAcar)_atl\%2001.pdf

BRASIL (2014). Portaria no 452, 20 novembro de 2014. Normas técnicas de ensaios para EPI. Retirado fevereiro, 3, 2006 de http://acesso.mte.gov.br/legislacao/2014.htm.

Buchholz, B., Frederick, L. J., \& Armstrong, T. J. (1988). An investigation of human palmar skin friction and the effects of materials, pinch force and moisture. Ergonomics, 31, 3, 317-325.

ECS - European Committee for Standardization (2003). BS EN 388: protective gloves against mechanical risks.

ECS - European Committee for Standardization (2003). BS EN 420: protective gloves - general requirements and test methods. 
Faccioli, I. (2009). Vozes do Eito. (Coletânea de depoimentos sobre a vivência cotidiana de migrantes temporários rurais). Guariba. ECO das Letras.

Ferreira, L. L. Gonzaga, M.C., Donatelli, S., \& Bussacos, M.A. (1998). A análise coletiva dos cortadores de cana da região de Araraquara. ( $2^{a}$ edição). São Paulo: Fundacentro.

Gonzaga, M. C. (2002). 0 uso dos equipamentos individuais de proteção e das ferramentas de trabalho no corte manual da cana de açúcar. Relatório Técnico. Retirado março, 12, 2013, de http:// pesquisa.fundacentro.gov.br/linkpdf/31138.pdf.

Gonzaga, M. C. (2004). 0 uso de luvas de proteção no corte manual de cana-de-açúcar. Dissertação (Mestrado em Engenharia Agrícola). Faculdade de Engenharia Agrícola, Universidade Estadual de Campinas, Campinas.

ISO - International Standard (1999). ISO 13999-1: protective clothing - gloves and arm guards protecting against cuts and stabs by hand knives - part 1: chain-mail gloves and arm guards.

ISO - International Standard (2003). ISO 13999-2: protective clothing - gloves and arm guards protecting against cuts and stabs by hand knives - part 2: gloves and arm guards made of material other than chain mail.

Muralidhar, A., Bishu, R. R., \& Hallbeck, M. S. (1999). The development and evaluation of an ergonomic glove. Applied ergonomics, 30(6), 555-563.

Neto, E. B., Resende, M., \& Álvares, R. (1989). Projeto de design de facão e luvas de proteção utilizadas no corte da cana-de-açúcar. Anais do $4^{\circ}$ Congresso Brasileiro de Ergonomia (pp. 169-171). Rio de Janeiro: ABERGO.

Veiga, M. M., Duarte, F. J. D. C. M., Meirelles, L. A., Garrigou, A., \& Baldi, I. (2007). Contamination by pesticides and Personal Protective Equipment (PPE). Revista Brasileira de Saúde Ocupacional, 32, 116, 57-68.

\section{NOTAS}

1. Portaria no 452 de 20 de novembro de 2014 (BRASIL, 2014) estabelece as normas para fabricação das luvas de proteção contra riscos mecânicos substituindo a Portaria 121.

2. Portaria $\mathrm{n}^{\circ} 452$ de 20 de novembro de 2014 (BRASIL, 2014) estabelece as normas para fabricação das luvas de proteção contra riscos mecânicos substituindo a Portaria 121.

\section{RESUMOS}

O presente estudo partiu de pesquisas anteriores a respeito do uso de luvas de proteção no corte manual da cana-de-açúcar. Analisa-se o processo de certificação de aprovação deste EPI, discutindo a problemática do distanciamento entre normas de ensaios para fabricação de equipamentos de proteção dos usuários e a atividade a ser exercida.

Destaca-se a importância do reconhecimento da variabilidade entre os tamanhos das mãos na seleção de luvas de proteção, assim como se enfatiza o número de acidentes e doenças ocupacionais registrados na atividade envolvendo mãos, justificando a relevância de seu uso. 
Observou-se como a principal ferramenta de trabalho - o facão - é readaptada pelos trabalhadores para ser utilizada com eficiência no processo produtivo. São apresentadas sugestões elaboradas pelos trabalhadores para aperfeiçoamento das luvas e do facão. À guisa de conclusão, identificam-se os desafios em reconhecer e discutir as dificuldades e limitações do uso de EPI e do sistema de certificação.

Este estudio toma como punto de partida investigaciones anteriormente realizadas sobre el uso de guantes de protección durante el corte manual de la caña de azúcar para analizar el proceso de certificación y aprobación de este EPP y para discutir la distancia existente entre las normas que rigen los ensayos para la fabricación de equipos de protección y la actividad que va a ser ejercida por sus usuarios. Se resalta la importancia de reconocer la variabilidad en el tamaño de las manos a la hora de seleccionar los guantes de protección y se enfatiza el número de accidentes y enfermedades ocupacionales que involucran las manos durante el ejercicio de esa actividad para justificar la importancia del uso de guantes. También se observó como los trabajadores readaptan el uso de su principal herramienta de trabajo - el machete - para aumentar la eficiencia durante el proceso productivo. Por último, se presentan sugerencias de los propios trabajadores para perfeccionar los guantes y el machete. A título de conclusión, se reflexiona sobre el desafío de reconocer y discutir las dificultades y limitaciones del uso de EPP y de su sistema de certificación.

Cette étude a été basée sur des recherches antérieures relatives à l'utilisation de gants de protection dans la coupe manuelle de la canne à sucre. Elle analyse le processus de certification de cet EPI et discute le problème de l'écart entre les normes d'essai pour la fabrication de ces équipements et l'activité à effectuer.

Elle met en évidence l'importance de reconnaître la variabilité entre les tailles des mains pour le choix des gants de protection et elle met aussi l'accent sur le nombre d'accidents et de maladies professionnelles enregistrées dans l'activité impliquant les mains, ce qui justifie la pertinence de son utilisation. À cette occasion, il a été noté comment le principal outil de travail - la machette est modifié par les travailleurs pour le rendre plus efficace et mieux adapté aux exigences du processus de production. L'étude présente des suggestions conçues par les travailleurs pour l'amélioration des gants et de la machette. En conclusion, on reprend les défis que soulève la reconnaissance des difficultés et des limites dans l'utilisation des EPI sans oublier ce qui relève du système de leur certification.

The present study is based on previous researches into the use of safety gloves in manual sugarcane harvesting. It analyses the certification and approval process of this PPE, discussing the issue of the distance between the test standards for the production of protective equipment for the users and the actual activity to be performed.

It highlights the importance of the recognition of the various sizes of hands to the selection of safety gloves, as well as it stresses the number of accidents and occupational diseases registered in the activity involving hands, justifying the relevance of their use. During the study, it was observed how the main work tool - the cutting blade - is readapted by the workers to be used with efficiency in the productive process. It presents suggestions made by the workers in order to improve the gloves and the cutting blade. At last, it points out the challenges of recognising and discussing the difficulties and limitations of the use of PPE and of its certification system. 
ÍNDICE

Mots-clés: gants, travail, santé, coupe manuelle de la canne à sucre

Palabras claves: guantes, trabajo, salud, corte manual de la caña de azúcar

Palavras-chave: luvas, trabalho, saúde, corte manual da cana-de-açúcar

Keywords: gloves, work, health, manual cutting of sugarcane

\section{AUTORES}

\section{MARIA CRISTINA GONZAGA}

Serviço de Ergonomia, Fundacentro - Ministério do Trabalho e Previdência Social, Rua Capote Valente,710, São Paulo, SP, Brasil

gonzaga@fundacentro.gov.br

\section{CRISTIANE QUEIROZ BARBEIRO LIMA}

Serviço de Ergonomia, Fundacentro - Ministério do Trabalho e Previdência Social, Rua Capote Valente,710, São Paulo, SP, Brasil

cristianequeiroz@fundacentro.gov.br 